\title{
'I am who I am’: Reputation concerns in adolescents on the autism spectrum
}

\section{Eilidh Cage ${ }^{1,2}$, Geoffrey Bird ${ }^{3,4} \&$ Liz Pellicano ${ }^{1,5}$}

${ }^{1}$ Centre for Research in Autism and Education (CRAE), Department of Psychology and Human Development, UCL Institute of Education, University College London, London, UK. ${ }^{2}$ Department of Psychology, Royal Holloway, University of London, Surrey, UK. ${ }^{3}$ MRC Social, Genetic \& Developmental Psychiatry Centre, Institute of Psychiatry, Kings College London, London, UK. ${ }^{4}$ Institute of Cognitive Neuroscience, University College London, London, UK. ${ }^{5}$ School of Psychology, University of Western Australia, Perth, Australia.

Correspondence concerning this article should be addressed to Eilidh Cage, Department of Psychology, Royal Holloway, University of London, Egham, Surrey, TW20 0EX,

Eilidh.cage@rhul.ac.uk 


\begin{abstract}
Background: Adolescence is often characterised by an increased concern for one's reputation in typical development. The extent to which autistic adolescents are concerned for their reputation, however, is unclear.
\end{abstract}

Method: Semi-structured interviews were conducted with 12 autistic adolescents and five members of school staff to examine reputation concerns in autism. Topics discussed included being 'cool', friendships, worries and self-concepts.

Results: Thematic analysis revealed that autistic adolescents were sometimes concerned about their reputation, although many reported that they did not want to be cool. Instead, they preferred to be true to themselves and struggled to understand the rules of being cool. Adolescents' difficulties in coping with unpredictability also contributed to their understanding of social rules. Findings were supported by the responses of school staff.

Conclusions: This study suggests that autistic adolescents can be concerned about their reputation, with some wishing to be accepted for having a reputation for being different.

Keywords: Reputation; adolescence; friendship; autism 


\section{Introduction}

Reputation is a social construct based on what others think of the self (Shaw, Li \& Olson, 2013). Being able to effectively manage reputation is an important skill for maintaining friendships and relationships with others (Barclay \& Willer, 2007; Tennie, Frith, \& Frith, 2010). Although young children may be capable of managing their reputations (Leimgruber, Shaw, Santos \& Olson, 2012), adolescence marks a number of social changes that may lead to increased concern for reputation (Sebastian et al., 2008). Intimate peer relationships tend to become increasingly valuable for adolescents (Jankowski et al., 2014) and there is an enhanced desire to avoid social exclusion (Blakemore \& Mills, 2014). For example, adolescents often change their behaviour when peers are present, such as by increasing risk taking (Chein, Albert, O'Brien, Uckert \& Steinberg, 2011; Gardner \& Steinberg, 2005). Accordingly, behaviour in adolescence may be driven, in part, by a need to manage reputation in front of peers.

Difficulties in social communication and interaction are hallmark features of autism (American Psychiatric Association, 2013). Adolescence can be a particularly difficult time for those on the autism spectrum, as they may struggle with the increased social complexities that the secondary school environment presents (Adreon \& Stella, 2001; Carrington et al., 2003a). Indeed, cognitively-able autistic $^{1}$ adolescents report increased concerns about their friendships and an increasing awareness that they are different to other people (Carrington et al., 2003b; Stoddart, 1999). They also report that they would like to fit in and have friends (Daniel \& Billingsley, 2010), although they often feel like they do not fit in (Portway \& Johnson, 2003) and lack the skills to successfully obtain desired friendships (Bauminger et al., 2003; Locke et al., 2010). As Milton (2013) notes, although the social experiences of autistic individuals are different to that of typical individuals, there is not necessarily a lack of interest in, or motivation for, social experiences, as is often assumed. For example, Carrington et al. (2003b) found that adolescents with autism reported using "masquerading" - pretending to know how social situations work - to hide their social difficulties from typical peers. Thus, it is plausible that autistic individuals would be to some degree concerned about what others think of them.

\footnotetext{
${ }^{1}$ The term 'autistic person' is the preferred language of many people on the spectrum (e.g. Sinclair, 1999). In this article, we use this term as well as person-first language to respect the wishes of all individuals on the spectrum (Kenny et al., 2015).
} 
Being able to understand peers' perspectives is a key skill for maintaining friendships (Blakemore \& Mills, 2014). Autistic individuals are known to struggle with automatically determining others' thoughts (Ruffman, Garnham \& Rideout, 2001; Senju, Southgate, White \& Frith, 2009) but may learn to master some perspective-taking skills (Bowler, 1992; Happé, 1995; Scheeren et al., 2013). There is also evidence that children with autism can self-promote (Begeer et al., 2008; Scheeren et al., 2010) - an ability that further suggests that autistic individuals may be somewhat concerned by how they are viewed by others. Furthermore, autistic adolescents are sensitive to social rejection: following ostracism in a cyber ball game, they were negatively affected in terms of anxiety, self-esteem and belonging, much like their typical peers (Sebastian, Blakemore \& Charman, 2009). Concern for reputation may lead to efforts to manage reputation; however, the evidence for reputation management in autism is currently mixed. While some authors suggest that autistic individuals cannot manage their reputation (Izuma, Matsumoto, Camerer \& Adolphs, 2011), other work (Cage, Pellicano, Shah, \& Bird, 2013) has suggested autistic adults are capable of reputation management, albeit to a lesser degree than typical adults. It may be the case that there are great individual differences in reputation concerns (and subsequently reputation management) in autism. Further work is clearly needed to enhance our understanding of this topic in autism, and to the best of our knowledge reputation concerns have not been specifically examined in autistic adolescents. Additionally, research generally into adolescence for those with autism is relatively sparse in comparison to research into children with autism.

Thus, the current study aimed to examine reputation concerns in autistic adolescents, since (a) adolescence appears to be a particularly potent time for reputation, as discussed above, and (b) we know little about reputation concerns in autistic adolescents. Given that this issue has been hitherto largely unexplored, in-depth qualitative methods were used to gain insight into autistic adolescents' social experiences and uncover any potential concern for reputation. Qualitative methods can provide a deeper understanding of reputation in autism from the perspective of autistic individuals themselves (Bölte, 2014), and highlight previously unconsidered explanations of reputation in autism in order to inform future experimental work. Qualitative methods can also empower individuals whose voices often go unheard (Carrington \& Graham, 2001) - and adolescent autistic voices are all too often unheard in autism research (Pellicano, Dinsmore \& Charman, 2014). Our previous quantitative work on reputation management (Cage et al., 2013) could not easily be explained by behavioural 
paradigms alone - suggesting that qualitative research can tell a story that cannot be told alone by numbers (Brown \& Lloyd, 2001). Therefore, we believe that qualitative methods are highly beneficial for understanding how autistic individuals themselves construct the world (Humphrey \& Lewis, 2008) and specifically their reputation.

We examined the social experiences of autistic adolescents, through semi-structured interviews, to assess whether these adolescents are concerned for their reputation. We elicited autistic adolescents' perceptions of being 'cool', friendships, worries, and their self-concept. We also interviewed school staff that supported some of the adolescents to provide an additional perspective on these adolescents' school-based social experiences.

\section{Method}

\subsection{Participants}

Twelve autistic adolescents (one female) took part aged between 12 and 15 years ( $\mathrm{M}$ age $=13$ years 9 months). All adolescents were attending mainstream secondary school and were considered to be cognitively able, such that their intellectual ability, measured using the WASI-II (Wechsler, 2011), was greater than 70 (Full-scale IQ: $\mathrm{M}=92.25, \mathrm{SD}=20.29$; Verbal IQ: $\mathrm{M}=91.42, \mathrm{SD}=20.17$;

Performance IQ: $M=94.08 ; S D=17.69)$. All adolescents had received an independent clinical diagnosis of either autism $(n=10)$ or Asperger syndrome $(n=2)$, according to DSM-IV criteria (APA, 2000) or ICD-10 (WHO, 1992) criteria, and further scored above the threshold for autism spectrum disorder (ASD) (score of 15) on the Social Communication Questionnaire (SCQ; Rutter et al., 2003). All students also had a statement of Special Educational Needs. Individual characteristics of participants are shown in Table 1.

--- Insert Table 1 here ---

Participants were recruited through specialised autism provisions attached to mainstream secondary schools in the London area. Five members of school staff (Learning Support Assistants (LSA); four female) who worked directly with some of the participating adolescents were also interviewed. 
Ethical approval was obtained from the Faculty of Policy and Society's Research Ethics Committee at the Institute of Education, London. Written informed consent was obtained from all participants (adolescents and school staff) prior to taking part, as well as parental consent for the adolescents.

2.2.

\section{Procedure}

2.2.1. Interview schedules. Adolescents' semi-structured interviews were developed in consultation with a senior LSA at one of the participating schools to ensure the questions would be developmentally appropriate. The interviews included questions about being cool (e.g., "what makes someone cool at your school?"), their friends (e.g., "what does being a friend mean to you?") and worries (e.g., "can you tell me about things that make you feel worried?"). Adolescents were also asked to describe themselves and to describe how they believed other people would describe them to examine their perceived self-concepts. The topic of being cool was chosen since a reputation for such is particularly pertinent for many typical adolescents (Danesi, 1994; Martino, 2000). Given the importance of friends during adolescence (Jankowski et al., 2014), reputation specifically amongst friends may be of great importance, even for adolescents with autism. Discussion of worries aimed to highlight concerns for reputation if the adolescents were to express concern over what others think. Examining their self-concepts, by asking them to describe themselves and to consider how others would describe them, elicited their degree of self- and other-awareness.

Following the recommendations of Harrington, Foster, Rodger, and Ashburner (2013), adolescents were given the opportunity to view the questions prior to the interview. They were also given a visual schedule to provide structure during the interview, which detailed the four main topics of the questions: school, friends, worries and "you".

The questions for LSAs focussed on their experiences of working with and supporting students on the autism spectrum (e.g., "how would you describe the students you work most with?"), students' friendships (e.g., "can you tell me about the friendships you witness?"), students' worries (e.g., "what kinds of things concern or worry the students you work with?") and the attitudes of their mainstream non-autistic students (e.g., "how do you think the other students without autism view the students with autism?"). 
2.2.2. General procedure. To begin, the researcher built rapport with the adolescents by visiting them at school and spending time with them in lessons and breaks over a 4-week period. Such rapport building prepared the adolescents for the interview experience and aimed to reduce any anxiety that could have arisen from participating in an unfamiliar situation with an unfamiliar adult (Harrington et al., 2013). During the week before the interviews took place, the researcher described the interview process in detail, ensured the adolescent understood the research and obtained written informed consent from them to take part in the project.

Both adolescents' and staff members' interviews took place during school hours in a quiet place and were recorded for later transcription. The length of adolescents' interviews ranged from 9 minutes to 26 minutes (mean $=15$ minutes) and LSAs' interviews ranged from 16 minutes to 25 minutes (mean $=$ 20 minutes). After completing the interview, the students completed the WASI-II (Wechsler, 2011) to establish cognitive ability.

2.3. Data analysis. NVivo was used to collate and organise the data. Thematic analysis was used to examine and identify themes within the interviews guided by the recommendations of Braun and Clarke (2006), which dictates six analysis steps: data familiarisation, generation of codes, searching for themes, reviewing themes, defining and naming themes and producing the report. A deductive approach was used, with data analysed at the semantic level; that is, themes were directed by our research question and identified themes reflected the actual content of the data. In other words, we wanted to test the hypothesis, highlighted by previous research, that reputation concerns may be possible in autism and, as such, we approached the analysis by coding statements that may be related to reputation concerns. The interviews were coded independently by two researchers and underlying themes were agreed upon following discussion across multiple meetings. All sentences or phrases were coded on first reading, and those relevant to the study's research question were reviewed further and grouped into themes.

\section{Results}

\subsection{Interviews with autistic adolescents}

Several themes, including reputation concerns, friendship and non-social challenges, were identified from adolescents' responses (see Figure 1). Given the potential depth of thematic analysis, here we 
primarily report the themes that reflected the majority of adolescents' responses. We do acknowledge, however, interesting cases where the theme was not shared by all participants, such as adolescents who stood out as reporting something different to the majority (see 3.1.2 for an example).

--- Insert Figure 1 here ---

3.1.1. Reputation concerns. Adolescents' discussions of their concerns about reputation yielded two subthemes: changing behaviour to make others like them and understanding and attitudes towards being cool.

Changing behaviour to make others like them. Five adolescents recalled a time where they had deliberately changed their behaviour to make others like them. For example, some reported that they had attempted to learn more about a particular topic: "I did try to look up more about games "cause my friends were always making funny references to games, so I tried to look up and find references to make as well". Another reported how he had misbehaved to impress others in the past: "I was kind of a bad boy back then, I used to do not good stuff, stuff I wasn't proud of, like I always used to try and act big to other students". Others noted changes in their behaviour (e.g., "well sometimes, sometimes I don't really want to") but were unable to explain how they changed their behaviour or why they did not want to change. Six adolescents said that they had not changed their behaviour to make others like them. Two adolescents expanded on this by describing how they were happy with how they were ("I'm fine the way I am" and "I just be who I am really [sic]").

Understanding and attitudes toward being cool. Seven adolescents reported that they did not want to be cool - because they did not understand the point of being cool and were not impressed by "coolness": "They're just all "look at me" and l'm just thinking what a bunch of idiots. You look at them, you just think "what's the point?", because you're making yourself look good, but it's not really helping you in any situations in life". Other adolescents went further and reported taking pride in not being cool: "People seem to follow people around all because it'll make them popular or because they like certain things. Well, I think I am who I am, and think what you want, and do what you want, but you're not going to change me. And if you have a problem with that that is your own problem". Accordingly, being true to one's self was one of the most common explanations for why the adolescents did not want to be seen as cool: "I just feel uncomfortable with this cool stuff going on anyway. I'm not interested at all. It's good to be who you are, I say". Others reported that they did not try to be cool 
because they did not understand the rules behind being cool; "I don't even know the rules. I just don't really care about being cool".

All of the adolescents could identify rules surrounding being cool. For example, several equated cool with being fashionable: "they've all got cool hairstyles and stuff". Bad behaviour was commonly discussed as a trait of cool people (e.g., "I don't like them [the cool kids]; they're really, really, naughty"). Finally, some noted positive benefits to being cool, including being able to make friends or having a special talent: "[other student] is cool; he is a computer genius".

3.1.2. Friendship. All adolescents reported having friends, although the number of friends varied widely. Five stated they had lots of friends. Three distinguished between close friends and casual acquaintances: "I've got two proper, proper, proper friends and l've got other friends, but I'm just really cool with them". One adolescent stated that he preferred his own company: "Most of the time I like to be myself, like if I'm with someone and I'm having fun and I'm talking to them that's good, but afterwards I tend to block it out".

We identified two sub-themes following adolescents' discussion of their friendships: their understanding of friendship and their awareness of their social challenges.

Understanding of friendship. All adolescents spoke of friendship and what friends meant to them, although there were times when many struggled to define friendship in itself: "I understand that I have friends but it's quite hard to understand the concept of it". Friendship was mostly equated with companionship, such as spending time with friends (e.g., "they always hang out with me"), sharing interests with friends (e.g., "it's very easy to talk to each other because we like very similar things") and helping one another (e.g., "it's good to have lots of people to talk to and to help you"). Half of the students also reported that friends gave them emotional support: "you can rely on each other, you can cheer each other up, and there's just someone there to help you and be friends with you, someone who cares". On the whole, the adolescents appeared to be satisfied with their friendships, with several claiming that if they had too many friends, difficulties could arise; "Someone [will] be all like, "oh this guy said this, and this guy said that" and then apparently "that's really rude, you swore at me" or something like that, and that's not really what I want. It's not exactly what I'm interested in. It just confuses me". 
Awareness of social challenges. The majority of adolescents identified social challenges they had faced. Some explained how making friends could be difficult: "Well it's actually tough to get your friends at first, it's tough to talk to them". Others found interacting with strangers challenging: "I like being with my friends and sometimes all by myself. I don't like working with new people". Two adolescents stated that they particularly disliked it when observed by others, for example: "when I'm playing cricket I hate it, I hate when I go in and then you see there's two of you and there's eleven fielders and they're all staring at you, and then all the people on the side are staring at you. Sometimes I stand there and my legs start shaking". Two adolescents noted that they worried about others disliking them, such as: "[I worry about] people liking me, and my friends never invite me to places. They always use the excuse that I'm not allowed". Finally, one adolescent described how he had used the internet to find others who faced similar social challenges to himself: "A lot of things on there [the internet] I can relate to, like struggling with things socially - having to act like you understand something when you don't".

3.1.3. Non-social challenges. Aside from social challenges, we identified two sub-themes relating to non-social challenges. In one sub-theme, many adolescents reported notable challenges related to school. These largely related to exams, tests, or homework (e.g., "family make me worried, [there is] pressure on to do well in your exams"), although one adolescent reported finding it difficult to cope with noise in the classroom: "It's very distracting when the class is being a bit noisy. I really don't like that at all".

In the second sub-theme, adolescents reported that they struggled with coping with unpredictability of everyday life, such as when teachers changed: "I don't like people leaving and then coming. It kind of confuses me. I just like it being all the same people, the same always". One adolescent described how he coped with unexpected situations by ensuring all of his belongings were organised in a certain way: "I like being in the same chair, with my diary, with my pencil case, neatly - ruler, pencil, pen, book, in front of me, any extra books on the side here like that, straight line".

3.1.4. Self-concept: Direct and reflected self-evaluation. All students gave a description of themselves (direct self-evaluation) and a description of how they thought other people would describe them (reflected self-evaluation), as shown in Table 2. The direct and reflected self-evaluations of the majority of adolescents overlapped considerably, but there were differences between direct and 
reflected self-evaluations. Four types of direct and reflected self-evaluation descriptions were identified, including physical, personality, behavioural and identity descriptions.

Direct self-evaluation. Most adolescents described themselves by referring to physical traits, for example, "[l'm] average height". Eight described themselves in terms of personality traits (e.g., "I'm jolly and sometimes l'm a bit negative"). Four described certain behaviours that they felt defined them, such as "I can joke around". Four reported some form of identity, such as just being themselves.

Reflected self-evaluations. Many referred to personality traits and behavioural traits when discussing how others would describe them. Only two said that others would describe them with reference to physical traits. Two referred to identity, for example: "in the geek group". Finally, two reported that they did not know how someone else would describe them.

--- Insert Table 2 here ---

\subsection{Interviews with LSAs}

Four main themes were identified from the interviews with LSAs, including a desire to fit in, friendships, non-social challenges and the challenge of living with autism in a neurotypical world (Figure 2).

- Insert Figure 2 here ---

3.2.1. Reputation concerns: Adolescents' desire to fit in. All five adults reported that they believed the adolescents with whom they worked were concerned about their reputation at times and had a desire to fit in. For example, LSAs noted that some of their students did not want to be seen as autistic by other students: "He still prefers to be in his main school form than come back here [to the autism provision] for form time. He sees it as more of a stigma coming back here. He wants to be seen as everyone else"; and "The one who has asked me before "why am I autistic", she gets very upset and very stressed, and she's like "you know to be one of the cool kids you have to wear this" [...] And she will do anything to be like one of the cool kids, including covering her face in makeup, which - it might be dripping - but it's the logic of you have to put makeup on in order to be cool".

3.2.2. Friendship. All LSAs could identify friendships amongst the adolescents with whom they worked but identified (1) differences in friendship quality and (2) difficulties in understanding social 
rules. LSAs discussed how they believed there to be a difference in the nature of autistic adolescents' friendships compared to those of typical adolescents. For example: "They have their friendships, so the two boys in our class who like London transport and buses, there is some form of friendship you can see there. It's not in the typical form of playing together but they have a shared interest". They described how their students found friendships difficult due to struggles in understanding everyday social rules: "I think that some of them are very aware of the fact that they find socialising very baffling, and it has to be learnt, and quite nerve-wracking because socialising is very unpredictable".

\subsubsection{The challenge of living with autism in a neurotypical world. All LSAs spoke of the} perceived challenges for their students of growing up autistic and how this impacted upon students' experiences of the world. When describing their students, all LSAs emphasised the variability amongst them: "I think "normal" is sort of the key word. That it's not normal, because autism is there's no normal, what is normal? You could get fifty kids with the same diagnosis and they're all completely different". All LSAs also noted challenges that autistic students faced in a mainstream school setting, specifically with reference to how they were perceived and (mis)understood by nonautistic students: "I think they [the mainstream students] would say that, yes, they're different but they're quirky different. I have picked up on a couple of students who've said "oh so-and-so's not normal" and I've said to them "actually, what is normal, you tell me what's normal", and when you ask a mainstream student that they're like "well, I don't know"'. Despite being perceived as different, all of the LSAs did believe that the autistic adolescents they worked with were accepted by the non-autistic students, for example: "You have got the handful, and it's quite a large handful, of students that are very accepting and won't even think of them being here as any different. They think of them as a [school] student not a [autism provision] student".

LSAs reported that despite their students being unique individuals, the students they worked with were nevertheless still teenagers - a period that all young people go through, regardless of whether they have autism: "They worry about friends, they worry about socialising, they worry about exams, tests - just the normal things that a teenage child would worry about, whether they've got autism or not, they all worry about the same things". Notwithstanding, the LSAs noted that having autism could make the experience of being a teenager all the more challenging: "[you are] generally wanting to fit in with your peers, but you have the added stress of being autistic". 
3.2.4. Non-social challenges: Coping with unpredictability. One LSA felt that the greatest challenge her students faced on a day-to-day basis was "dealing with everyday life and the unpredictability of everyday life". The LSAs described specific incidents of students struggling to cope with unpredictability: "[They struggle with] transition, moving from one place to another, movement along the corridors, assemblies, lunch times, how are they going to occupy themselves. So they tend to really stick rigidly to what they always do and they will not bend".

\subsection{Integrating viewpoints.}

The perspectives of adolescents and school staff overlapped considerably. Notably, both could give evidence of reputational concerns and both also noted a preference for creating order to cope with potentially unpredictable and unexpected circumstances. They also both reported that friendships could pose particular difficulties and challenges. Further, both described everyday challenges at school, which lend toward the idea of some universal experiences as "teenagers". One interesting area of divergence was that some adolescents reported that they preferred to be true to themselves, but their LSAs felt differently, suggesting that many of them had a desire to fit in.

\section{Discussion}

This study examined potential concern for reputation through the use of in-depth qualitative interviews with autistic adolescents and the school staff who support them. We found significant variability in the extent to which adolescents were concerned about their reputation, which appeared to be related either to a desire to be true to oneself or to difficulties in understanding of social rules and their function.

Responses from both autistic adolescents and school staff suggested that the adolescents were capable of being concerned about their reputation. Many of them were aware of and at times concerned for their reputation, with some discussing specific changes in behaviour they had made to impress others. This finding supports previous research with adults with autism (Cage et al., 2013) and experimental research evidencing self-presentation skills in children with autism (Begeer et al., 2008; Scheeren et al., 2010). These studies evidence an awareness and concern for reputation in autism. 
It has been argued that a concern for one's reputation is reliant upon Theory of Mind (ToM; Izuma, 2012), the ability to think about others' thoughts (Baron-Cohen et al., 1985). Research has supported the proposition that autistic individuals specifically have problems with implicit but not explicit ToM (Callenmark, Kjellin, Rönnqvist \& Bölte, 2014; Frith, 2004; Senju et al., 2009). In other words, autistic individuals may be able to pass some tests of ToM, perhaps through better language skills, compensatory strategies or experience (Happé, 1995), but do not automatically consider other minds. Evidence for this suggestion has been demonstrated in studies showing that autistic adults pass traditional tests of ToM, but do not show anticipatory gaze towards the false belief location, unlike typical adults and 3-year-olds (Senju et al., 2009; Ruffman, Garnham \& Rideout, 2001). These results suggest that adolescents with autism may have the ability to explicitly think about their reputation in the eyes of others, but may be less likely to spontaneously do so.

We examined reputation by focussing on the topic of being cool, as many typical adolescents strive for a reputation of being cool (Danesi, 1994; Martino, 2000; Martino \& Pallotta-Chiarolli, 2005). The autistic adolescents could identify what it meant to be cool, yet more than half stated that they did not want to be cool. This lack of a desire to be seen as cool could be due to either to a preference for being authentic or to difficulties in understanding social rules.

In terms of authenticity, many adolescents reported that they would rather be true to themselves than seen as cool, with several taking pride in their differences and being "who I am". Previous research has noted that some autistic individuals take pride in their differences and in neurodiversity (Humphrey \& Lewis, 2008; Hurlbutt \& Chalmers, 2002; Jaarsma \& Welin, 2012; Robertson, 2009). Appreciating these differences, rather than attempting to fit autistic people into a standard conception of "normality", is perhaps key in enhancing understanding of how autistic individuals experience the social world (Milton, 2012). Other researchers (Frith \& Frith, 2011; Schereen et al., 2010) have also suggested that reputation management may not occur in autism due to a preference for honesty or authenticity. Together with the current findings, we suggest that some autistic adolescents may choose not to change their behaviour based on others' thoughts or feelings in order to be authentic.

It is also worth considering an alternative possibility: that the interview itself may have elicited reputational concern in these adolescents. It is possible that those who reported that being different or authentic was important to them may not have been identifying to the interviewer how they truly feel, 
but rather how they believed they should feel, that is, they acted in a socially desirable way.

Consistent with this possibility, school staff were not necessarily in agreement with this preference of the adolescent's to remain true to themselves. Instead, they reported that their students had a desire to fit in. Previous research has also noted this desire to belong (Daniel \& Billingsley, 2010), with one study reporting that autistic adolescents used masquerading to fit in with their peers (Carrington et al., 2003b). It is possible that these adolescents do have some motivation to fit in with their peers, but they do not wish to do so by conforming. Rather, as one student noted, they would like to be accepted for being different: "if they don't like someone because they're different, well that to me isn't necessarily cool". The results imply a conflict for adolescents who want to fit in with others but also want to be accepted for being different.

Difficulties in understanding social rules could also contribute to the likelihood of reputation concerns in autism. Some adolescents reported difficultly in understanding the rules surrounding being cool, and LSAs also described how their students were often "baffled" by social rules. Understanding social rules could be related to explicit ToM (Frith \& Frith, 2008) with autistic individuals explicitly learning about certain social rules. The current findings imply, however, that something more than ToM is needed to explain reputation concerns in autism. Even if social rules can be explicitly learnt, autistic adolescents may still find it difficult to keep track of what may constitute a cool reputation. Previous research has shown that autistic children can have knowledge of social rules but are less flexible than typical children in applying social rules during moral reasoning (Shulman, Guberman, Shiling \& Bauminger, 2012; Brewer et al., in press). Autistic adolescents and LSAs reported that coping with unpredictability was a challenging aspect of everyday life. Individuals with autism are known to be resistant to change (APA, 2013), which could be underpinned by difficulties in coping with unpredictability in the environment (Pellicano, 2013). This difficulty could contribute to difficulties in understanding social rules, and ultimately, the propensity to be concerned for and manage reputation.

In the current study, teaching staff reported that the autistic students were largely accepted by their peers, although their non-autistic peers often perceived the autistic students as being different. Previous research has suggested that autistic adolescents often feel that their differences are viewed negatively by typical peers (Humphrey \& Lewis, 2008) and typical adolescents acknowledge that being seen as normal is a key aspect of secondary school social life (Martino \& Pallotta-Chiarolli, 
2005) - suggesting that having a reputation for being different may be less accepted by typical adolescents. One limitation of this study is that we did not directly compare the perspectives of autistic adolescents with non-autistic adolescents. Future research should attempt to examine the potential differences in reputation management between these two groups.

The current study also examined autistic adolescents' friendships. All adolescents reported that they had friends and understood different aspects of friendship, such as companionship and emotional support. Nonetheless, they were aware of the social challenges they faced when it came to making friends. For example, several noted how they found it difficult to make new friends, how strangers and observation could cause anxiety, and reported worries over others liking them. LSAs further reported that their students' friendships had a different quality to typical students' friendships. Previous research has noted similar aspects of friendship in autism (Bauminger et al., 2003; Calder et al., 2013; Carrington et al., 2003b; Daniel \& Billingsley, 2010; Locke et al., 2010), which could support the idea that friendships may be a reputational incentive for those with autism, such that some autistic adolescents want and enjoy having friends, and may be motivated to manage their reputation for these friends. Indeed, some autistic adolescents mentioned that they had, for example, researched computer games more to make their friends like them. It is important to note that some of the adolescents expressed that they preferred their own company (see also Calder et al., 2013) and found social situations anxiety provoking. High social anxiety frequently co-occurs in autism (Kuusikko et al., 2008; White et al., 2009). Understanding precisely how social anxiety interacts with reputation management is a potential avenue for future research. Those who are more socially anxious may have a greater concern about what others' think about their reputation.

Finally, adolescents' direct and reflected self-evaluations were considered to establish how the adolescents saw themselves and how they thought others saw them. In adolescence, how the self is defined is thought to be heavily dependent upon how others define us (Sebastian et al., 2008). One would therefore expect significant overlap between direct and reflected self-evaluations (Felson, 1993; Pfeifer, Masten, Borofsky, Dapretto, Fuligni \& Lieberman, 2009), which is precisely what we found. There appeared to be a shift, however, from describing the self in terms of personality and physical traits when giving direct self-evaluations, to referring to personality and behavioural traits (e.g., being good at playing video games) when asked how others would describe them. These 
differences in self-evaluations suggest that these adolescents are aware that they have a reputation, with others describing them differently to how they describe themselves. Some found it difficult to discuss how other people would describe them, which could relate to ToM or language ability. Nonetheless, autistic adolescents do have a self-concept (Lee \& Hobson, 1998), which appears to have some relation to how they are seen by others (i.e. their reputation). This extent and nature of their self-concepts, and how they might different from those of typical adolescents, is a worthy avenue for future research.

\subsection{Limitations}

The current study is limited by a small sample size - although it is worth noting that a sample size is deemed appropriate for in-depth qualitative research such as this study (Guest, Bunce \& Johnson, 2006). It could also be argued that our sample is highly heterogeneous, composed of individuals with discrepancies between their verbal mental age and chronological age, therefore limiting the generalisation of the current study. However, we argue that such heterogeneity is inherent in autism and examining a group of individuals who have different levels of ability is in fact more representative of the autistic population than if the current study were to focus only on highly verbal autistic individuals. The adolescents with lower verbal ability could still answer all of the questions and describe their social lives - statements from their teachers also evidenced reputation concerns in these students. Nonetheless, the findings of this study should be used to inform new hypotheses (i.e. that autistic adolescents can be concerned about their reputation) that can be tested with larger sample sizes and experimental methods, rather than to generalise. We also acknowledge that a comparison group of typical adolescents would be useful in clarifying concerns for reputation in this population too - for example, whether typical adolescents have differing attitudes to the notion of being cool.

\subsection{Implications}

Overall, the current study enabled examination of a previously neglected area of research: reputation concerns in autistic adolescents. This study indicated that reputation concerns are present in some adolescents on the autism spectrum. Yet, variability in reputation concerns appeared to stem from a desire to be authentic and difficulties in understanding social rules and their function. The contribution of these factors to reputation in autism has not previously been considered. Notably, autistic 
adolescents in the current sample found coping with the unpredictability of everyday life and understanding subtle and unwritten social rules a substantial challenge. Furthermore, being seen as different was discussed by many adolescents. Being different, however, is often not accepted by typical adolescents (Humphrey \& Lewis, 2008; Martino \& Pallotta-Chiarolli, 2005), therefore these results may have implications for inclusion practices by challenging what most typical adolescents consider "normal". Given the high rates of bullying in autism (Roekel, Scholte, \& Didden, 2010), with autistic adolescents reporting that encounters with peers can be frequently hostile or negative (Carrington et al., 2003b; Williamson, Craig \& Slinger, 2008), teaching typical children the positives of diversity (and neurodiversity) could be one way of improving autism acceptance. Finally, this study demonstrates the importance of enabling young people on the autistic spectrum to speak out about their social experiences, in this instance by revealing new insights into reputation concerns in autism. 


\section{Acknowledgements}

We are very grateful to all of the young people, parents and schools involved in this research. Thanks also to Nora Choque-Olson for assistance with data coding. The work was supported by a Bloomsbury Colleges PhD studentship awarded to the first author. Research at CRAE is also supported by The Clothworkers' Foundation and Pears Foundation. The funding sources had no involvement in the study design, collection, analysis, interpretation, writing or decision to submit.

The authors have no conflict of interest to declare.

\section{References}

Adreon, D., \& Stella, J. (2001). Transition to Middle and High School: Increasing the Success of Students with Asperger Syndrome. Intervention in School and Clinic, 36(5), 266-271.

American Psychiatric Association (2000). Diagnostic and Statistical Manual of Mental Disorders (Fourth edition). Arlington, VA: American Psychiatric Publishing.

American Psychiatric Association (2013). Diagnostic and Statistical Manual of Mental Disorders (Fifth edition). Arlington, VA: American Psychiatric Publishing.

Barclay, P., \& Willer, R. (2007). Partner choice creates competitive altruism in humans. Proceedings of the Royal Society B: Biological Sciences, 274(1610), 749-753.

Baron-Cohen, S., Leslie, A. M., \& Frith, U. (1985). Does the autistic child have a theory of mind? Cognition, 21, 37 - 46 .

Bauminger, N., Cory, S., \& Agam, G. (2003). Peer interaction and loneliness in high-functioning children with autism. Journal of Autism and Developmental Disorders, 33(5), 489 - 507.

Begeer, S., Banerjee, R., Lunenburg, P., Meerum Terwogt, M., Stegge, H., \& Rieffe, C. (2008). Brief report: Self-presentation of children with Autism Spectrum Disorders. Journal of Autism and Developmental Disorders, 38(6), 1187-1191.

Blakemore, S-J., \& Mills, K. L. (2014). Is adolescence a sensitive period for sociocultural processing? Annual review of psychology, 65, 187-207.

Bölte, S. (2014). The power of words: Is qualitative research as important as quantitative research in the study of autism? Autism, 18(2), 67-68.

Bowler, D. M. (1992). "Theory of Mind" in Asperger's Syndrome. Journal of Child Psychology and Psychiatry, 33(5), 877-893. 
Braun, V., \& Clarke, V. (2006). Using thematic analysis in psychology. Qualitative Research in Psychology, 3(2), 77-101.

Brewer, R., Marsh, A., Catmur, C., Cardinale, E.M., Stoycos, S., Cook, R. \& Bird, G. (in press). The impact of Autism Spectrum Disorder and alexithymia on judgments of moral acceptability. Journal of Abnormal Psychology.

Brown, C., \& Lloyd, K. (2001). Qualitative methods in psychiatric research.Advances in Psychiatric Treatment, 7(5), 350-356.

Cage, E., Pellicano, E., Shah, P., \& Bird, G. (2013). Reputation management: evidence for ability but reduced propensity in Autism. Autism Research, 6(5), 433-442.

Calder, L., Hill, V., \& Pellicano, E. (2013). "Sometimes I want to play by myself": Understanding what friendship means to children with autism in mainstream primary schools. Autism, 17(3), 296316.

Callenmark, B., Kjellin, L., Rönnqvist, L., \& Bölte, S. (2014). Explicit versus implicit social cognition testing in autism spectrum disorder. Autism, 18(6), 684-693.

Carrington, S., \& Graham, L. (2001). Perceptions of school by two teenage boys with Asperger syndrome and their mothers: A qualitative study. Autism, 5(1), 37-48.

Carrington, S., Papinczak, T., \& Templeton, E. (2003a). A phenomenological study: The social world of five adolescents who have Asperger's syndrome. Australian Journal of Learning Disabilities, 8(3), 15-20.

Carrington, S., Templeton, E., \& Papinczak, T. (2003b). Adolescents with Asperger syndrome and perceptions of friendship. Focus on Autism and Other Developmental Disabilities, 18(4), 211218.

Chein, J., Albert, D., O'Brien, L., Uckert, K., \& Steinberg, L. (2011). Peers increase adolescent risk taking by enhancing activity in the brain's reward circuitry. Developmental Science, 14(2), F1F10.

Danesi, M. (1994). Cool: The signs and meanings of adolescence. Canada: University of Toronto Press.

Daniel, L. S., \& Billingsley, B. S. (2010). What Boys With an Autism Spectrum Disorder Say About Establishing and Maintaining Friendships. Focus on Autism and Other Developmental Disabilities, 25(4), 220-229. 
Felson, R. B. (1993). The (somewhat) social self: How others affect self-appraisals. Psychological perspectives on the self, 4, 1-26.

Frith, C. D., \& Frith, U. (2008). Implicit and Explicit Processes in Social Cognition. Neuron, 60(3), 503510.

Frith, C. D., \& Frith, U. (2011). Mechanisms of social cognition. Annual Reviews of Psychology, 63, 287-313.

Frith, U. (2004). Emanuel Miller lecture: Confusions and controversies about Asperger syndrome. Journal of Child Psychology and Psychiatry, 45(4), 672-686.

Gardner, M., \& Steinberg, L. (2005). Peer influence on risk taking, risk preference, and risky decision making in adolescence and adulthood: An experimental study. Developmental psychology, 41(4), 625.

Guest, G., Bunce, A., \& Johnson, L. (2006). How many interviews are enough? An experiment with data saturation and variability. Field methods, 18(1), 59-82.

Happé, F. G. E. (1995). The Role of Age and Verbal Ability in the Theory of Mind Task Performance of Subjects with Autism. Child Development, 66(3), 843-855.

Humphrey, N., \& Lewis, S. (2008). 'Make me normal'. Autism, 12(1), 23-46.

Humphrey, N., \& Parkinson, G. (2006). Research on interventions for children and young people on the autistic spectrum: a critical perspective. Journal of Research in Special Educational Needs, 6(2), 76-86.

Hurlbutt, K., \& Chalmers, L. (2004). Employment and adults with Asperger syndrome. Focus on autism and other developmental disabilities, 19(4), 215-222.

Izuma, K. (2012). The social neuroscience of reputation. Neuroscience Research, 72(4), 283-288.

Izuma, K., Matsumoto, K., Camerer, C. F., \& Adolphs, R. (2011). Insensitivity to social reputation in autism. Proceedings of the National Academy of Sciences, 108(42), 17302-17307.

Jaarsma, P., \& Welin, S. (2012). Autism as a natural human variation: Reflections on the claims of the neurodiversity movement. Health Care Analysis, 20(1), 20-30.

Jankowski, K. F., Moore, W. E., Merchant, J. S., Kahn, L. E., \& Pfeifer, J. H. (2014). But do you think I'm cool?: Developmental differences in striatal recruitment during direct and reflected social self-evaluations. Developmental Cognitive Neuroscience, 8, 40-54. 
Kenny, L., Hattersley, C., Molins, B., Buckley, C., Povey, C., \& Pellicano, E. (2015). Which terms should be used to describe autism? Perspectives from the UK autism community. Autism, 1362361315588200.

Kuusikko, S., Pollock-Wurman, R., Jussila, K., Carter, A., Mattila, M.-L., Ebeling, H., Pauls, D.L., \& Moilanen, I. (2008). Social anxiety in high-functioning children and adolescents with autism and Asperger syndrome. Journal of Autism and Developmental Disorders, 38(9), 1697-1709.

Lee, A., \& Hobson, R. P. (1998). On Developing Self-concepts: A Controlled Study of Children and Adolescents with Autism. Journal of Child Psychology and Psychiatry, 39(8), 1131-1144.

Leimgruber, K. L., Shaw, A., Santos, L. R., \& Olson, K. R. (2012). Young children are more generous when others are aware of their actions. PLOS ONE, 7(10), e48292.

Locke, J., Ishijima, E. H., Kasari, C., \& London, N. (2010). Loneliness, friendship quality and the social networks of adolescents with high-functioning autism in an inclusive school setting. Journal of Research in Special Educational Needs, 10(2), 74-81.

Martino, W., \& Pallotta-Chiarolli, M. (2005). Being normal is the only way to be: Adolescent perspectives on gender and school. Sydney: University of New South Wales Press.

Martino, W. (2000). Mucking around in class, giving crap, and acting cool: Adolescent boys enacting masculinites at school. Canadian Journal of Education/Revue canadienne de l'education, 25(2), 102-112.

Milton, D. (2013). An exploration into 'autspace'. Retrieved 8th October 2013 from http://blog.talkaboutautism.org.uk/2013/10/an-exploration-into-autspace.html.

Milton, D. (2012). On the ontological status of autism: the 'double empathy problem'. Disability \& Society, 27(6), 883-887.

Molloy, H., \& Vasil, L. (2002). The social construction of Asperger syndrome: The pathologising of difference? Disability \& Society, 17(6), 659-669.

Pellicano, E. (2013). Sensory Symptoms in Autism: A Blooming, Buzzing Confusion? Child Development Perspectives, 7(3), 143-148.

Pellicano, E., Dinsmore, A., \& Charman, T. (2014). What should autism research focus upon? Community views and priorities from the United Kingdom. Autism, 18(7), 756-770. 
Pfeifer, J. H., Masten, C. L., Borofsky, L. A., Dapretto, M., Fuligni, A. J., \& Lieberman, M. D. (2009). Neural correlates of direct and reflected self-appraisals in adolescents and adults: When social perspective-taking informs self-perception. Child Development, 80(4), 1016-1038.

Portway, S., \& Johnson, B. (2003). Asperger Syndrome and the children who don't quite Fit. Early Child Development and Care, 173(4), 435-443.

Robertson, S. M. (2009). Neurodiversity, quality of life, and autistic adults: Shifting research and professional focuses onto real-life challenges. Disability Studies Quarterly, 30(1). http://dsqsds.org/article/view/1069.

Roekel, E., Scholte, R. J., \& Didden, R. (2010). Bullying Among Adolescents With Autism Spectrum Disorders: Prevalence and Perception. Journal of Autism and Developmental Disorders, 40(1), 63-73.

Ruffman, T., Garnham, W., \& Rideout, P. (2001). Social Understanding in Autism: Eye Gaze as a Measure of Core Insights. Journal of Child Psychology and Psychiatry, 42(8), 1083-1094.

Rutter, M., Bailey, A., Berument, S. K., Lecouteur, A., Lord, C., \& Pickles, A. (2003). Social Communication Questionnaire (SCQ). Los Angeles, CA: Western Psychological Services.

Scheeren, A. M., Begeer, S., Banerjee, R., Meerum Terwogt, M., \& Koot, H. M. (2010). Can you tell me something about yourself?: Self-presentation in children and adolescents with high functioning autism spectrum disorder in hypothetical and real life situations. Autism, 14(5), 457-473.

Scheeren, A. M., de Rosnay, M., Koot, H. M., \& Begeer, S. (2013). Rethinking theory of mind in highfunctioning autism spectrum disorder. Journal of Child Psychology and Psychiatry, 54(6), 628635.

Sebastian, C., Blakemore, S.-J., \& Charman, T. (2009). Reactions to Ostracism in Adolescents with Autism Spectrum Conditions. Journal of Autism and Developmental Disorders, 39(8), $1122-$ 1130.

Sebastian, C., Burnett, S., \& Blakemore, S.-J. (2008). Development of the self-concept during adolescence. Trends in Cognitive Sciences, 12(11), 441-446.

Senju, A., Southgate, V., White, S., \& Frith, U. (2009). Mindblind Eyes: An Absence of Spontaneous Theory of Mind in Asperger Syndrome. Science, 325(5942), 883-885. 
Shaw, A., Li, J., \& Olson, K. R. (2013). Reputation Is Everything. In M. R. Banaji \& S. Gelman (Eds.), Navigating the Social World: What Infants, Children, and Other Species Can Teach Us (pp. 220 - 224). New York: Oxford University Press.

Shulman, C., Guberman, A., Shiling, N., \& Bauminger, N. (2012). Moral and Social Reasoning in Autism Spectrum Disorders. Journal of Autism and Developmental Disorders, 42(7), 13641376.

Stoddart, K. P. (1999). Adolescents with Asperger Syndrome Three Case Studies of Individual and Family Therapy. Autism, 3(3), 255-271.

Tennie, C., Frith, U., \& Frith, C. D. (2010). Reputation management in the age of the world-wide web. Trends in Cognitive Sciences, 14(11), 482-488.

Wechsler, D. (2011). Wechsler Abbreviated Scale of Intelligence (2nd ed.). San Antonio, TX: Pearson.

White, S. W., Oswald, D., Ollendick, T., \& Scahill, L. (2009). Anxiety in children and adolescents with autism spectrum disorders. Clinical Psychology Review, 29(3), 216-229.

Williamson, S., Craig, J., \& Slinger, R. (2008). Exploring the relationship between measures of selfesteem and psychological adjustment among adolescents with Asperger Syndrome. Autism, 12(4), 391-402.

World Health Organization (1992). The ICD-10 classification of mental and behavioural disorders: clinical descriptions and diagnostic guidelines. Geneva: World Health Organization. 
Table 1.

Individual characteristics of each participant, including gender, chronological age, verbal mental age, and Social Communication Questionnaire (SCQ) scores, diagnosis, age of autism diagnosis and ethnicity.

\begin{tabular}{|c|c|c|c|c|c|c|}
\hline Gender & $\begin{array}{l}\text { Chronological } \\
\text { age (years: } \\
\text { months) }\end{array}$ & $\begin{array}{c}\text { Verbal } \\
\text { mental } \\
\text { age }^{1}\end{array}$ & $\begin{array}{l}\text { SCQ } \\
\text { score }^{2}\end{array}$ & Diagnosis $^{3}$ & $\begin{array}{l}\text { Age of } \\
\text { autism } \\
\text { diagnosis } \\
\text { (months) }\end{array}$ & Ethnicity \\
\hline Female & 12: 9 & $8: 3$ & 33 & $\begin{array}{l}\text { Autism Spectrum } \\
\text { Disorder }\end{array}$ & 40 & White - British \\
\hline Male & 13: 4 & 15: 9 & 32 & Asperger's Syndrome & 118 & White - other \\
\hline Male & 14: 11 & 13: 0 & 20 & $\begin{array}{l}\text { Autism Spectrum } \\
\text { Disorder }\end{array}$ & 48 & $\begin{array}{l}\text { White \& Black } \\
\text { African }\end{array}$ \\
\hline Male & 12: 10 & 9: 10 & 27 & Autism & 59 & $\begin{array}{c}\text { British Asian \& } \\
\text { East African }\end{array}$ \\
\hline Male & 13: 10 & 15: 10 & 25 & Autism, ADHD & 58 & White - British \\
\hline Male & 13: 10 & 13: 0 & 21 & $\begin{array}{l}\text { Autism Spectrum } \\
\text { Disorder, Dyspraxia }\end{array}$ & 43 & White - British \\
\hline Male & 13: 2 & 10: 2 & 32 & Autism & 60 & White - British \\
\hline Male & 15: 9 & 14: 10 & 31 & Autism, ADHD & 84 & White - British \\
\hline Male & 15: 0 & 10: 0 & 25 & $\begin{array}{l}\text { Autism Spectrum } \\
\text { Disorder }\end{array}$ & 36 & White/Asian \\
\hline Male & 12: 11 & & 29 & Autism, Dyspraxia & 84 & $\begin{array}{c}\text { White - } \\
\text { British/Asian }\end{array}$ \\
\hline Male & 12: 11 & & 28 & $\begin{array}{l}\text { Autism Spectrum } \\
\text { Disorder }\end{array}$ & 24 & White - British \\
\hline Male & 13: 9 & 16: 10 & 28 & $\begin{array}{l}\text { Asperger's Syndrome, } \\
\text { ADHD, depression, } \\
\text { anxiety disorder }\end{array}$ & 87 & White - British \\
\hline
\end{tabular}

Note. ${ }^{1}$ Verbal mental age was calculated by dividing verbal IQ by chronological age, and then multiplying by 100 . IQ was measured using the WASI-II. ${ }^{2}$ Cut off score for SCQ is 15 . ${ }^{3}$ Diagnoses were reported by parents. 
Table 2. Direct ("how would you describe yourself") and reflected ("how would other people describe you") self-evaluations made by all of the autistic students.

\begin{tabular}{|c|c|c|c|c|}
\hline ID & Direct self-evaluation & Category & Reflected self-evaluation & Category \\
\hline 101 & $\begin{array}{l}\text { "I say that I look more } \\
\text { beautiful than you" } \\
\text { "Not wearing nail varnish" }\end{array}$ & Physical & $\begin{array}{l}\text { "They say I look more lovely than } \\
\text { any other children" } \\
\text { "I think my best friend would } \\
\text { describe me... like... I look very } \\
\text { beautiful with this blazer and my } \\
\text { school trousers" }\end{array}$ & Physical \\
\hline 102 & $\begin{array}{l}\text { "Average height, I think... not } \\
\text { very strong" } \\
\text { "Smart", "Cheeky" }\end{array}$ & $\begin{array}{l}\text { Physical } \\
\text { Personality }\end{array}$ & $\begin{array}{l}\text { "I'll go for smart again" } \\
\text { "Pretty much ... um in the geek } \\
\text { group" }\end{array}$ & $\begin{array}{l}\text { Personality } \\
\text { Identity }\end{array}$ \\
\hline 103 & $\begin{array}{l}\text { "I'm slick, very nice, quick, } \\
\text { fiery, loyal" }\end{array}$ & Personality & $\begin{array}{l}\text { "Well people describe me as nice, } \\
\text { but sometimes I can a be a little } \\
\text { bit of a jerk-off" } \\
\text { "Arrogant, only care about myself" } \\
\text { "Very vain. I'm always concerned } \\
\text { about my looks" }\end{array}$ & Personality \\
\hline 104 & "Just a regular, regular kid" & Identity & $\begin{array}{l}\text { "Popular maybe [...] you know, } \\
\text { cool" }\end{array}$ & Personality \\
\hline 105 & $\begin{array}{l}\text { "I'm jolly and sometimes I'm a } \\
\text { bit negative I have to admit... } \\
\text { a bit nervous, shy" } \\
\text { "Not very good at work" } \\
\text { "A bit overweight" }\end{array}$ & $\begin{array}{l}\text { Personality } \\
\text { Behavioural } \\
\text { Physical }\end{array}$ & $\begin{array}{l}\text { "I honestly don't know" } \\
\text { "Some people would say jolly or } \\
\text { happy and caring and now then } \\
\text { someone might say l'm a bit too } \\
\text { negative" } \\
\text { "He's fine, he's quite funny" } \\
\text { "He's alright at gaming" }\end{array}$ & $\begin{array}{l}\text { Personality } \\
\text { Behavioural }\end{array}$ \\
\hline 106 & $\begin{array}{l}\text { "I'm funny" } \\
\text { "I'm kind to my friends } \\
\text { sometimes" } \\
\text { "I'm just I just be who I am } \\
\text { really" } \\
\text { "I'm not very good describing } \\
\text { myself too. I just don't really } \\
\text { like describing myself, it's } \\
\text { better to know someone in } \\
\text { person think what does he } \\
\text { look like" }\end{array}$ & $\begin{array}{l}\text { Personality } \\
\text { Behavioural } \\
\text { Identity }\end{array}$ & $\begin{array}{l}\text { "Usually my friends say l'm funny" } \\
\text { "I'm trustworthy and very good to } \\
\text { be trusted [sic]. I don't lie often" }\end{array}$ & $\begin{array}{l}\text { Personality } \\
\text { Behavioural }\end{array}$ \\
\hline 107 & $\begin{array}{l}\text { "I'm getting big as well" } \\
\text { "I'm friendly and sometimes } \\
\text { funny" } \\
\text { "I'm a teenager" }\end{array}$ & $\begin{array}{l}\text { Physical } \\
\text { Personality } \\
\text { Identity }\end{array}$ & "You know friendly, maybe funny" & Personality \\
\hline 108 & $\begin{array}{l}\text { "l'd say I would have some } \\
\text { rugby build I would say" } \\
\text { "l'd like to say quite friendly to } \\
\text { people" } \\
\text { "I can joke around" }\end{array}$ & $\begin{array}{l}\text { Physical } \\
\text { Personality } \\
\text { Behavioural }\end{array}$ & $\begin{array}{l}\text { "Sometimes we always like annoy } \\
\text { each other, so people would say } \\
\text { I'm annoying" } \\
\text { "Mum mostly she would say that } \\
\text { you've got a big build for rugby, } \\
\text { and I just I just go with it" }\end{array}$ & $\begin{array}{l}\text { Behavioural } \\
\text { Physical }\end{array}$ \\
\hline 109 & $\begin{array}{l}\text { "[Own name] is good" } \\
\text { "I like having conversations" }\end{array}$ & Behavioural & "Good" & Behavioural \\
\hline 110 & $\begin{array}{l}\text { "Quite friendly and like a nice } \\
\text { person, kind and like } \\
\text { accommodating. I'm friendly } \\
\text { and like good friend to have } \\
\text { maybe" } \\
\text { "I'm not sure about height } \\
\text { because l'm not fully grown" } \\
\text { "I don't really know" }\end{array}$ & $\begin{array}{l}\text { Personality } \\
\text { Physical }\end{array}$ & $\begin{array}{l}\text { "I don't know it's confusing. I don't } \\
\text { know how other people would } \\
\text { describe me because l'm like- } \\
\text { there are a few people who don't } \\
\text { like me and they obviously wont } \\
\text { describe me in the best way but } \\
\text { like there's only few people who } \\
\text { sort of like me. I don't even know } \\
\text { they don't really know much about }\end{array}$ & $\begin{array}{l}\text { Personality } \\
\text { Identity }\end{array}$ \\
\hline
\end{tabular}




\begin{tabular}{|c|c|c|c|c|}
\hline & & & $\begin{array}{l}\text { me so they're not really going to } \\
\text { describe me anyway" } \\
\text { "I mean [friend] might say l'm a } \\
\text { nice person and stuff" } \\
\text { "My old school friends they let } \\
\text { people be themselves and stuff" }\end{array}$ & \\
\hline 111 & $\begin{array}{l}\text { "I am... good, I'm never a } \\
\text { bully" }\end{array}$ & Personality & $\begin{array}{l}\text { "Like a very nice friend, good } \\
\text { friend" }\end{array}$ & Personality \\
\hline 112 & $\begin{array}{l}\text { "When people ask me to like } \\
\text { describe myself I tend to } \\
\text { shudder "cause I can't really } \\
\text { think of anything specific. } \\
\text { One thing l'd say would be I } \\
\text { am who I am, and I do what I } \\
\text { do, and I like what I like" }\end{array}$ & Identity & $\begin{array}{l}\text { "See I don't know because when } \\
\text { I'm asked that kind of question } \\
\text { "how would someone else } \\
\text { describe them" I can never know } \\
\text { 'cause I've no idea what they're } \\
\text { thinking I can assume [...] No } \\
\text { matter how close they are I'm I } \\
\text { wouldn't be able to know how } \\
\text { they would describe me" }\end{array}$ & Personality \\
\hline
\end{tabular}

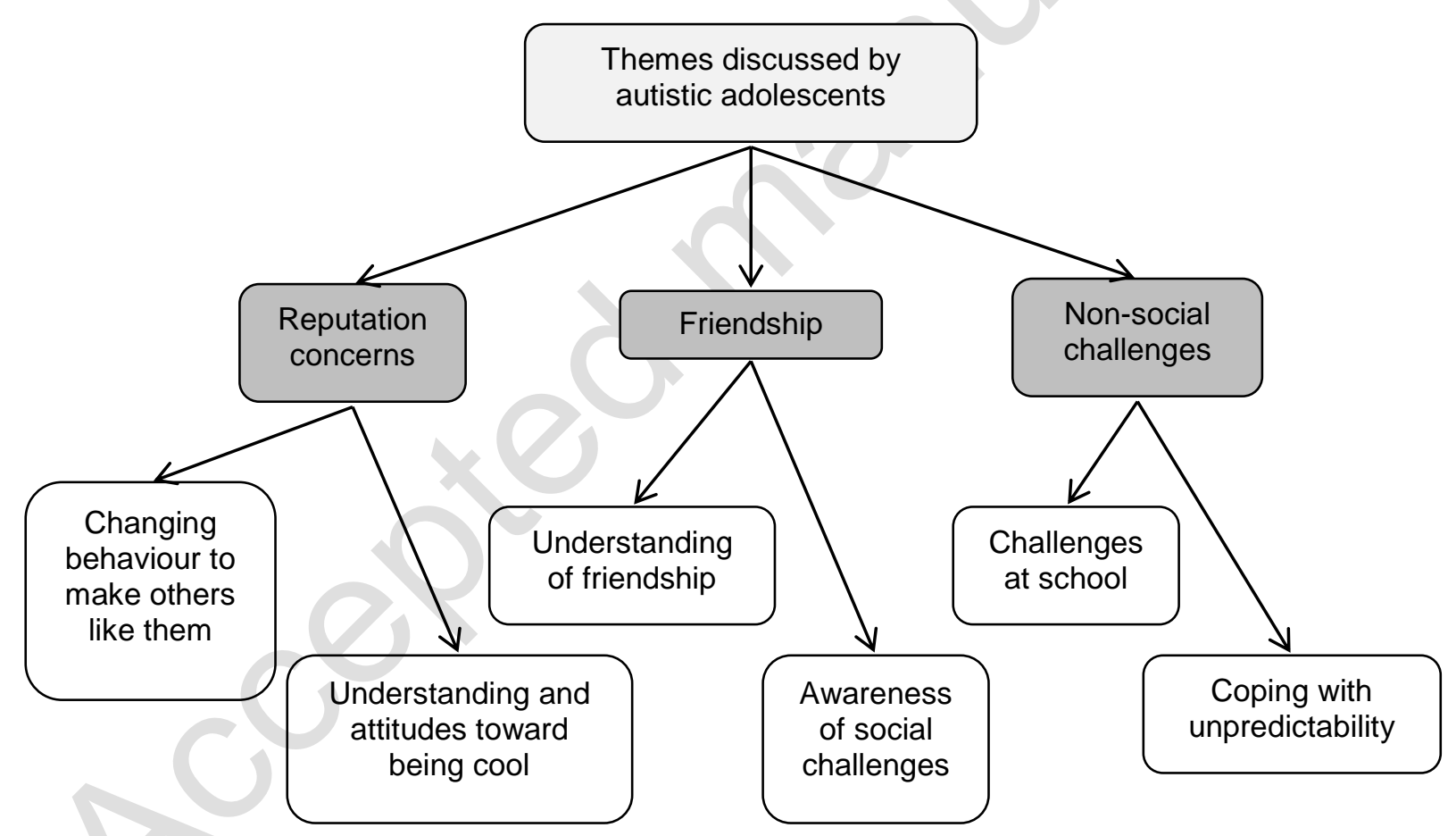

Fig. 1. Themes and sub-themes discussed by autistic adolescents. 


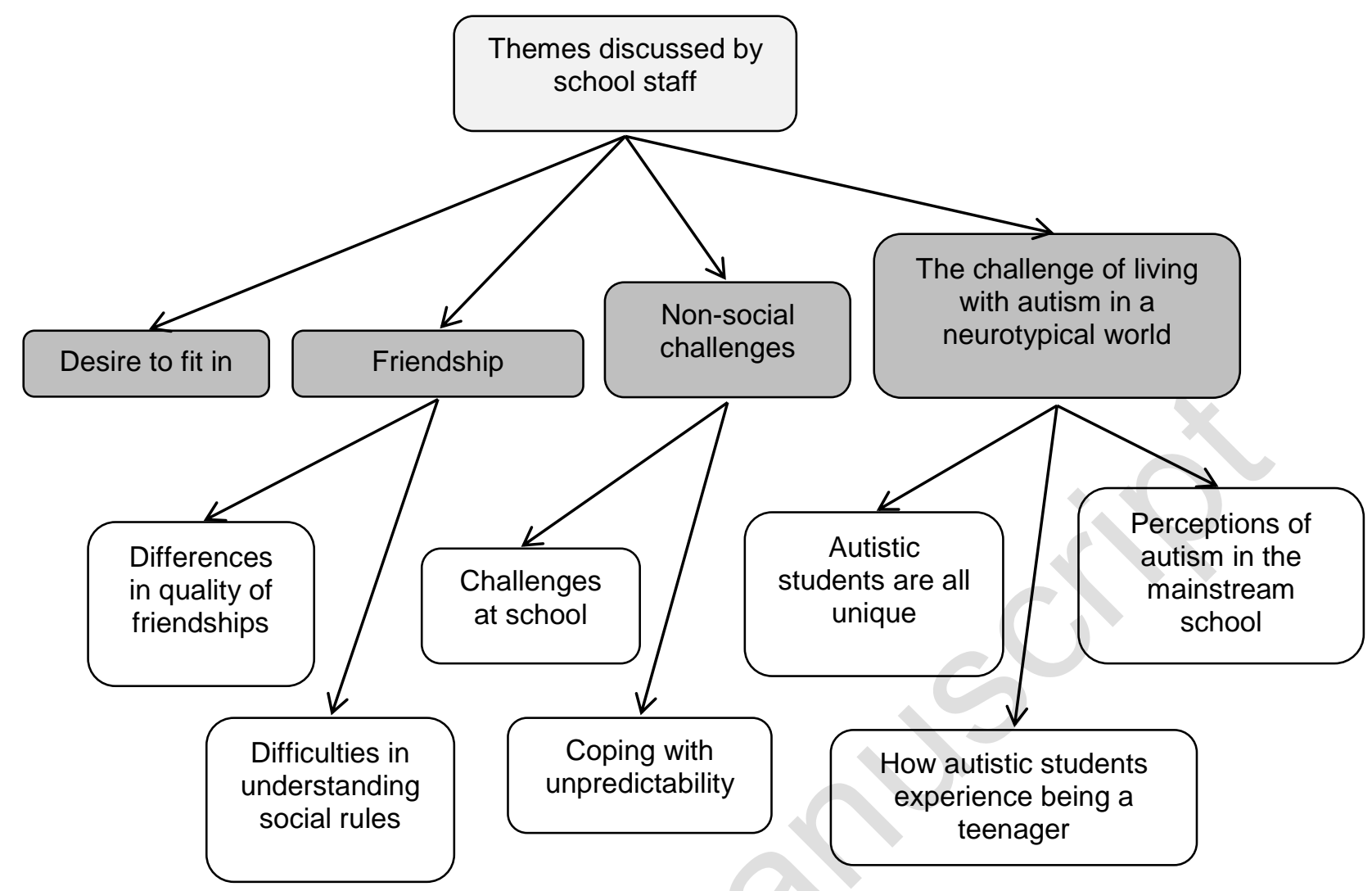

Fig. 2. Themes and sub-themes discussed by school staff 